\title{
VECTOR DENSITY AND SANITATION IN HIGH DENGUE HEMORRHAGIC FEVER ENDEMIC AREA IN TEMBALANG DISTRICT, SEMARANG, CENTRAL JAVA
}

\author{
Martini, Sri Yuliawati, Retno Hestiningsih, Nissa Kusariana, \\ Susiana Purwantisari
}

Faculty of Public Health, Universitas Diponegoro, Semarang

\begin{abstract}
Background: Dengue Haemorrhagic Fever (DHF) is a major public health problem in Tembalang, Semarang, Central Java. The cumulative incidence was reported to be 207.57/ 100,000 population by 2016. Aedes sp as a vector has an important role in the transmission of DHF in Tembalang District. This study aimed to describe vector density and sanitation indicators related to DHF incidence in Tembalang, Semarang, Central Java.

Subjects and Method: This was a cross sectional study. A sample of $12 \mathrm{DHF}$ endemic villages in Tembalang, Semarang, Central Java, was selected for this study. The study variables were vector density, biological environment, and Maya index. The data were collected by observation and checklist. The data were described by percent.

Results: The density of mosquito larvae in Tembalang was high with House Index $(\mathrm{HI})=21.17 \%$, Container Index $(\mathrm{CI})=50 \%$, and Breteau Index $(\mathrm{BI})=13.8 \%$, respectively. Based on larvae density index, Tembalang had high risk in DHF transmission. Aedes albopictus was found in the study area. One third of all larvae found were Aedes aegypti. Tembalang had poor sanitation. Maya index indicated the level of cleanliness and sanitation. $23 \%$ of houses that fall in these categories had been infected with DHF.

Conclusion: Tembalang has high risk in DHF transmission with poor sanitation. One third of all larvae found are Aedes aegypti. It is important to eradicate mosquito nest both indoor and outdoor, through active community participation.
\end{abstract}

Keywords: Dengue Hemorrhagic Fever, Maya index, Aedes sp mosquito

\section{Correspondence:}

Martini. Faculty of Public Health, Universitas Diponegoro, Semarang, Central Java. Email: tinihen65@yahoo.co.id. Mobile: 081225128032. 